\title{
Erratum to "Irradiance and Developmental Stages of Crown Architecture Affect Shoot Production in Rhododendron reticulatum" [American Journal of Plant Sciences 4 (2013) 69-76]
}

\author{
Kenichi Yoshimura \\ Center for Ecological Research, Kyoto University, Otsu, Japan \\ Email: y.shimuken@gmail.com
}

Received 12 March 2013; revised 15 April 2013; accepted 1 May 2013

Copyright (C) 2014 by author and Scientific Research Publishing Inc.

This work is licensed under the Creative Commons Attribution International License (CC BY).

http://creativecommons.org/licenses/by/4.0/

c) (i)

Open Access

The original online version of this article (Yoshimura, K. (2013) Irradiance and Developmental Stages of Crown Architecture Affect Shoot Production in Rhododendron reticulatum. American Journal of Plant Sciences, 4, 69-76. http://dx.doi.org/10.4236/ajps.2013.45A011) was published as a single-author paper mistakenly. To reflect the contribution and responsibility of the second author as well as the affiliations of the authors at the time of the study, we have revised the authorship and author affiliations of this article. The author wishes to correct the errors as:

\footnotetext{
Kenichi Yoshimura1,2, Hiroaki Ishii ${ }^{1}$

${ }^{1}$ Graduate School of Science and Technology, Kobe University, Kobe, Japan

${ }^{2}$ Present Address: Center for Ecological Research, Kyoto University, Otsu, Japan

Email: y.shimuken@gmail.com
} 